\title{
LOS RESTOS DE \\ INDUSTRIA HUMANA DE MIRAMAR
}

A propósito de los despropósitos del comandante Romero

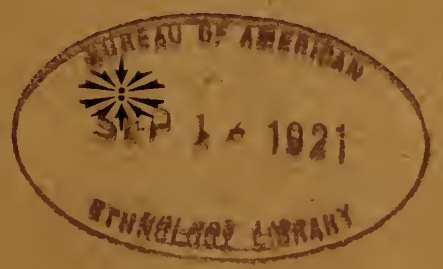

BUENOS AIRES

Hist.० Gr.० "OCEANA" - Chile 525

1919 



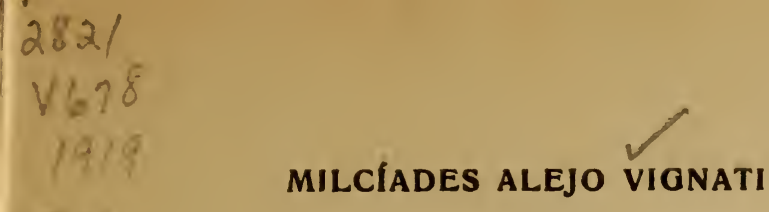

MILCÍADES ALEJO VIGNATI

\section{LOS RESTOS}

DE

\section{INDUSTRIA HUMANA \\ DE}

\section{MIRAMAR}

A propósito de los despropósitos

del comandante Romero

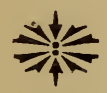

BUENOS AIRES

Est. Gr.० "OCEANA" - Chile 525

1919 



\section{A la \\ Sociedad Científica Argentina \\ con el fin de que estime en todo \\ su valor el mérito de los \\ colaboradores que acepta \\ y patrocina.}





\section{ADVERTENCIA}

Todos los que, conscientes del deber que impone la verdad científica y la dignidad propia publican folletos para discutir opiniones, están contestes en deciarar que los ataques personales no refuerzan los argumentos y desvían la discusión. Esta opinión, sustentada por todos los verdaderos cultores de la ciencia, es mantenida como es lógico, por los miembros de la Sociedad Científica Argentina, y, como tenemos conocimiento de los tijeretazos que por esta causa ha sufrido el panfleto que contestamos, hacemos la presente publicación para rechazar con entera libertad los ataques de carácter personal y pseudocientíficos del Comandante Romero, a fin de establecer de una vez por todas, el valor empírico de sus publicaciones pasadas y venideras. 

El indiscutible interés despertado por los hallazgos realizados en Miramar ${ }^{2}$, que han aportado a las discusiones paleoantropológicas una valiosa contribución, puede, tal vez, de reflejo, exagerar la importancia de un estudio recientemente aparecido ${ }^{3}$, en el que la insuficiencia científica apenas disfraza los desahogos personales del autor. Sería, pues, el caso de no preocuparse de esos inocuos ladridos a la luna, si la seriedad de la revista que los ha acogido y la personalidad científica a que van dedicados, no exigieran una crítica que, aunque superficial, sea suficiente para demostrar la notoria incapacidad de quién, de otro modo, pudiera

${ }^{1}$ Sabido es que el partido y ciudadela que en la toponimia po. pular se conocen como Miramar, corresponden en la nomenclatura oficial a General Alvarado.

2 ANTONIO A. ROMERO, El Homo pampaeus. Oontribución al estudio del origen $\boldsymbol{y}$ antigliedad de la raza humana on Sud América segin recientes descubrimientos, en Anales de la Sociedad Oientifica Argentina, LXXXVI, 5 y siguientes. Buenos Aires, 1918. 
ser tomado como un exponente de la ciencia argentina.

No, seguramente, por el estudioso que, por simple lectura, podrá apreciar la preparación geológica de quién llega a afirmar que nada significa la presencia de huesos fósiles, articulados ${ }^{1}$, aún cuando esos restos, cuando están in situ, son el rasgo más seguro para determinar la edad del terreno en que se encuentran. Añádase a aquella afirmación la extrañeza con que acoge el hecho de que, en la reducida altura de una barranca de pocos metros, estén representados estratos de varios pisos, imaginando, sin duda, que es forzoso que siempre aparezcan acumulaciones, altas como montañas, de un mismo eștrato y éstos siempre de igual potencia ${ }^{2}$. Basta lo

\footnotetext{
1 ROMERO, Ibld., 24. El párrafo a que hacemos referencia dice que «el hallazgo de piezas más o menos completas, y aun parte de un esqueleto, no significa otra cosa más, de que ese fué el término final de su arrastre en ese estado, y no el lugar en que el animal habia perecido». Tan infundada es la sentencis, que creemos inútil hacer referencias de los tratados de geología $y$ paleontología, tanto más, que ha de bastar al autor-dada su procedencia - la siguiente consideración, que sanchescamente nos parece viene como anillo al dedo: or, comme parmi ces débris il $\mathrm{g}$ a des carapaces de glyptodontidés entières où presque entières et des squelettes articulés, l'affirmation de cet auteur résulte être une de ces erreurs que rien n'excuse. (Confr. FLORENTINO AMEGHINO, Une nouvelle industrie de la pierre fendue dans le tertiaire de la région littorale au Sud de Mar del Plata, en Anales del Museo Nacional de Buenos Aires, [XX], serie III, XIII, 191. Buenos Aires, 1911 [1910]).
}

${ }^{2}$ ROMERO, Ibid., 42 y siguiente. 
enunciado para negạr al autor la competencia neceesaria para emitir parecer en estos asuntos.

Pero los profanos, los innúmeros aficionados que, con más buena voluntad que sólidos fundamentos, siguen, a la distancia, la marcha de estos estudios, tal vez pudieran aceptar sin mayor examen las conclusiones de aquel artículo, tanto más cuanto que se presentan como incondicional defensa de unas mal comprendidas teorías de Florentino Ameghino, de cuya obra el autor se proclama esforzado campeón y en cuya difusión, asegura, le ha cabido principal parte. $Y$, ya que, aunque nada importa al asunto, tanto se ufana de méritos tan cacareados como deșconocidos, habrá que recordarle que, fuera de Tarascón, resulta ridículo el papel de Tartarin orgulloso de haber cantado, en casa del boticario, el dúo de «Roberto el Diablo».

En gracia, sin embargo, a la brevedad y al buen gusto, será conveniente no curarse de esos infantiles engreimientos del autor $y$, no detenernos tampoco a recoger los insultos que prodiga a sus adversarios, pasando sin más preámbulos a avalorar la consistencia de la tesis que sustenta.

Para entrar cómodamente en materia, conviene hacer una recapitulación de los argumentos aducidos para «probar la falta de fundamento científico con que se pretende demostrar la existencia del 
hombre con pleno dominio intelectual en la remotísima edad del mioceno (hallazgos de Miramar) ${ }^{1}$. El lector agradecerá ciertamente, el trabajo y la paciencia de quien salga a campear, entre el extenso y tupido pajonal de frases y aventuras, los dispersos argumentos del Sr. Romero, los cuales, una vez reunidos, se concretan en unas cuantas afirmaciones que, aisladamente, procuraremos rebatir.

Comiénzase por afirmar que «los artefactos han sido enterrados en tiempo posterior a la formación del piso», lo cual no puede menos de ser así, puesto que más adelante se asegura que dicho piso, llamado chapadmalense en el Acta, fué «formado en el fondo del mar» ${ }^{2}$. A esto debe añadirse que es «realmente incomprensible» atribuir a «los artífices de los hallazgos arqueolíticos, una existencia permanente en el lugar, o mejor dicho en ese punto, equivalente al transcurso de tiempo exigido para alcanzar la sedimentación de cinco metros» ${ }^{8}$. Mientras que, en cambio, dando por seguro que «sobre la barranca ha existido una gran laguna, y en su orilla ha vivido una tribu de aborígenes» ${ }^{4}$, es evidente que éstos deben ser considerados como autores de los objetos encontrados. Esta evidencia haría más patente e indiscutible la relativa edad

1 ROMERO, Ibid., 9.

2 ROMERO, Ibid., 27 y siguiente.

'ROMERO, Ibid., 32.

'ROMERO, Ibid., 34. 
moderna de los hallazgos, aceptando, a ojos cerrados, en lo que respecta al terreno, la afirmación de que «el trozo de barranca de los artefactos no está constituído por los elementos que informa el Acta» ${ }^{1}$ $y$, en lo que toca a «los objetos de la industria humana descubiertos al sur de Miramar», la seguridad de que «son contemporáneos con los que se encontraron al sur del arroyo de Las Brusquitas»", no fijándose mayormente en la materia con que han sido hechos, puesto que el material utilizado no implica contemporaneidad con quien los trabaj6 ".

Teniendo a la vista los argumentos que quedan consignados, será tarea más fácil y más concluyente seguir paso a paso el raciocinio con que el Sr. Romero ha llegado a esas conclusiones y presentar en cada oportunidad las objeciones pertinentes. Pero ante todo para imponer al lector de la mala fe con que el Sr. Romero ha confeccionado su requisitoria, será conveniente comprobar como, en sus manos, la más clara exposición tórnase obscura y expresa precisamente lo contrario que en realidad afirmaba. Para llegar a esos asombrosos resultados, bástale al Sr. Romero recurrir a un procedimiento de falsifi-

\footnotetext{
${ }^{1}$ ROMERO, IbId., 41.

${ }^{2}$ ROMERO, Ibid., 45.

${ }^{3}$ ROMERO, IbId., 48.
} 
cación de textos que, si pone muy por encima su audacia, nada bueno dice de la honestidad científica que ha podido animarle. Cotéjese los párrafos que se transcriben a continuación y se verá hasta dónde llega la increíble audacia del Sr. Romero.

«Se dice en el acta que: -Basados en este hecho, el primer punto de la cuestión del peritaje quedó establecido en el siguiente tenor: que la inspección ocular del sitio donde se encontraron los artefactos referidos, no ha dado motivo para suponer que estos hayan sido enterrados por una u otra circunstancia en tiempo poste. rior a la formación de la capa; que se encontraban en posición primaria y que por lo tanto deben considerarse como objetos de industria humana contemporáneos al piso geológico en que se hallaron CONTRA LA BARRANCA $y$ corresponde a un piso superior de la formación pampeana, los firmantes declaran: que las condiciones estratigráficas son en este lugar tan claras que no presentan ninguna difi-
«Basados en este hecho, el primer punto de la cuestión del peritaje quedó establečido en el siguiente tenor: que la inspección ocular del sitio donde se encontraron los artefactos referidos, no ha dado motivo para suponer que éstos hayan sido enterrados por una $u$ otra circunstancia en tiempo posterior a la formación de la capa; que se encontraban en posición primaria y que por lo tanto deben considerarse como objetos de industria humana, contemporáneos al piso geológico en que se hallaron depositados.

Respecto al segundo punto de la cuestión del peritaje, es decir, si había la posibilidad que existiera en dicho lugar una yuxtaposición, es decir, si la capa que contiene los artefactos ha sido depositada contra una antigua 
cultad para resolver el problemas ${ }^{2}$. barranca y corresponde a un piso superior de la formación pampeana, los firmantes declaran: que las condiciones estratigráficas son en este lugar tan claras que no presentan ninguna dificultad para resolver el problema.

La comisión de geólogos está de acuerdo en que el segundo punto de la cuestión del peritaje puede definirse en la siguiente forma: que los objetos de industria humana se encuentran en este lugar en depósitos de loess característico del horizonte eopampeano, que constituye la base de la barranca; que la relación estratigráfica se presenta en condición tal, QUE SE PUEDE ESTA. BLECER A CIENCIA CIERTA QUE AQUI NO EXISTE UNA YUXTAPOSICION»?

${ }^{1}$ ROMERO, Ibid., 27.

' SANTIAGo ROTH, WALTHER SCHILLER, LUTZ WITTE, M. KANTOR, LUIS MARIA TORRES Y CARLOS AMEGHINO, Acta de los hechos más importantes del descubrimiento de objetos, instrumentos $y$ armas de pledra, realizado en las barrancas de la costa de Miramar, partido de General Alvarado, provincia de Buenos Aires, en LA DIRECCION [DEL MUSEO NACIONAL DE 
A pesar de la clara y terminante conclusión del Acta acerca de la naturaleza del terreno y de la imposibilidad de que se trate de un terreno placado, todo lo contrario resulta precisamente, gracias a la adulteración del Acta que el Sr. Romero brinda a sus lectores como fiel transcripción ${ }^{2}$. No nos detengamos, sin embargo, a censurar ese procedimiento que, por inaceptable que sea, sólo engañará a los crédulos ignorantes que a la manera de las víctimas del vulgar «cuento del tío», movidos por la codicia de encontrar errores, pagarán como bueno el grosero fajo de billetes falsos. No hagamos,

HISTORIA NATURAL DE BUENOS AIRES], Nuevas investigaclones geológicas 8 antropológicas en el litoral maritimo sur de la provincia de Buenos Aires. Anales del Museo Nacional de Historia Natural de Buenos Aires, XXVI, 422, Buenos Aires, 1915. (Siem. pre que se cite este documento se hará bajo el rubro de Acta).

1 Otro tanto acontece con la copia del Acta que inserta, según nos dice, «integramente», pero que, a pesar de tal rotunda afirmación, presenta olvidos como el que a continuación puede constatarse:

«Esta capa está separada de la barranca principal por un zanjón, pero se puede ver que descansa sobre un banco de loess muy consistente del horizonte mesopampeano y que forma la parte superior DE LA COSTA, y que en los puntos más altos no pasa de diez metros de altura》 (ROMERO, Ibid., 18)

\&Esta capa está separada de la barranca prineipal por un zanjón, pero se puede ver que descansa sobre un banco de loess muy consistente del horizonte mesopampeano $y$ que forma la parte superior DE LA BARRANCA DE LA COSTA, y que en los puntos más altos no pasa de diez metros de altura.) ( $A C$ ta, 420). 
pues, mayor caso de esas habilidades y pasemos a estudiar tomándolas en serio, las ideas del Sr. Romero.

En opinión del Sr. Romero, los artefactos no fueron hallados en situación primaria, sino enterrados en tiempo posterior a la formación del piso, y que fueron removidos a consecuencia de un «derrumbe de ese extremo de la barranca que afectó también a las capas superiores, cambiándolas de posición y dándoles inclinaciones diversas». Dicho derrumbe resultaría comprobado por la existencia, en capas del chapadmalense, de un estrato aislado de rodados, de poca potencia, en posición «casi vertical»; mientras que, en el ensenadense, es fácil ver otro estrato de rodados, semejante al anterior $\mathrm{y}$, como él, «formado en el lecho del mar», pero cuya posición con la horizontal acusa un ángulo de $16^{\circ} 45^{\prime} »^{\prime}$. Esta diferencia de posición entre los dos estratos es la que denuncia el derrumbe que, convulsionando el suelo implica que los objetos están en situación secundaria respecto al yacimiento.

Sin insistir en ello, nótese la enormidad que entraña la idea de contemporaneidad entre dos estratos, uno del piso ensenadense y el otro del chapadmalense, y baste afirmar que el estrato de tosquilla rndada que se sitúa al sud de la barranca no existe,

${ }^{1}$ ROMERO, Ibid., 28 y siguiente. 
para que todo el raciocinio que en él se apoya caiga, privado de base de sustentación. El examen más prolijo no ha conseguido comprobar su presencia; sin embargo, en el deseo de patentizar la inconsistencia de la tesis emitida, se puede llevar la buena voluntad hasta los límites de la credulidad ciega y admitir la existencia del estrato vertical de tosquilla que el Sr. Romero dice haber descubierto, bien que nadie haya conseguido verlo.

Si se tiene en cuenta que los estratos de tosquilla tienen una dirección diferente de casi un cuadrante (el uno casi vertical y el otro casi horizontal), los «plegamientos u ondulaciones orogénicas de la región» que han plegado tan violentamente el «paralelismo» de los estratos que se consideran sincrónicos, - a pesar de pertenecer uno al chapadmalense y otro al ensenadense, - tendrían que revelarse en ese mismo lugar en todas las demás capas de estratos; pero, según todas las fotografías y la propia narración que motiva esta réplica, las deposiciones del ensenadense y del chapadmalense no han sufrido las mismas variaciones que las tosquillas, cuyo violento plegamiento debieran reflejar; tanto más inverosímil resulta esto, cuanto que el plegamiento tendría que realizarse en los pocos metros que median entre unas tosquillas $y$ otras!

Es indudable que el movimiento tectónico ha existido, y ya hace tiempo Florentino Ameghino 
reconoció que el «abajamiento del suelo no es el resultado de denudaciones, sino de origen tectónico» ${ }^{1}$. Pero este movimiento ha existido para toda la región y no exclusivamente para la barranca de los hallazgos, y es por eso que «las capas del chapalmalense, siguiendo la inclinación hacia el sur, desaparecen hundiéndose en las aguas del Atlántico más o menos a mitad distancia entre el Arroyo de las Brusquitas y el Arroyo del Durazno»". Y si se quiere prueba más evidente que los movimientos tectónicos se han realizado sin la dislocación que se ha supuesto, adviértase que slas capas del ensenadense (pampeano inferior) como en su inclinación hacia el sur acompañan al chapalmalense, bajan hasta el nivel del Atlántico, hundiéndose bajo el nivel del agua precisamente en el mismo punto en donde desaparece el chapalmalense, esto es, a mitad distancia del Arroyo de las Brusquitas y el Arroyo del Durazno» ${ }^{3}$. No es, pues, en el lugar dèl supuests estrato de tosquillas donde el chapadmalense desaparece bajo la playa, sino más al sud y, por lo tanto, nada autoriza a formular la hipótesis de un derrumbe que cambiara la colocación de los

1 FLORENTINO AMEGHINO, Las formaciones sedimentarlas de la región litoral de Mar del Plata y Chapalmalán, en Anales del Museo Nacional de Buenos Aires, [XVII], serie III, $X, 380$, Buenos Aires, 1909 [1908].

2 AMEGHINo, Las formaciones, etc., 381.

- AMEGHINO, Las formaciones, etc., 381. 
objetos. Pero, ya que no puede subsistir esa hipótesis, i es, al menos, cierta la afirmación que esos estratos de tosquilla se formaron en el fondo del mar y que, por lo tanto, el terreno en que se encuentran es de formación marina?

En la lámina número III, reproduce el Sr. Romero la figura 1 del Acta de los peritos, y, - modificando los trazos de la cubierta - señala el límite de los pisos chapadmalense y ensenadense con localizasión de denudaciones y torrenteras. Ese mismo esquema ha de bastarnos para comprobar que, aún en el caso de que existiese el consabido estrato, en modo alguno se le puede atribuir origen marino.

En efecto: en el esquema, el estrato de tosquillas tiene, como límite superior, el mismo límite que los pisos chapadmalense y ensenadense, lo cual indica que «antes de la deposición del ensenadense, el suelo del continente chapalmalense fué surcado y denudado por fuertes corrientes de agua que arrastraron la parte superior y cavaron en la superficie cañadones profundos de distintas formas, $y$ son los que constituyen las irregularidades que presenta el límite o plano superior de la división inferior» ${ }^{1}$. $Y$ es por eso que «la base del ensenadense presenta a menudo capas de tosquilla y arcilla endurecida. reducida en fragmentos rodados

\footnotetext{
${ }^{1}$ AMEGHIXO, I:as formaciones, etc., 374 .
} 
por las aguas que los ha depositado en el fondo de las depresiones de erosión de la superficie del chapalmalense» ${ }^{*}$. De existir, pues, el estrato que se dice, en situación casi vertical, todo indicaría que se habría formado, por obra de corrientes terrestres, en el fondo de un cañadón ${ }^{2}$.

Otro tanto puede decirse del segundo estrato, señalado por los peritos que subscriben el Acta cuando dicen que «en algunas partes se notan estratificaciones y capas de rodados, compuestas en gran parte de tosquilla. El aspecto litológico de este depósito es el de las calizas de agua dulce, muy común en el horizonte mesopampeano» ${ }^{3}$. Y, más adelante, añaden: «el mencionado banco de caliza de agua dulce, que corresponde al horizonte mesopampeano y que se halla encima de los depósitos eopampeanos, no ha sufrido alteración ninguna; no se

1 AMEGHINO, Las formaciones, etc., 374.

2 Téngase en cuenta, que cu,alquiera que hubiera sido la posicí́n del pseudo-estrato en el piso chapadmalense, es decir: que no fuera un cañadón sino que fuera una capa horizontal, ello no invalidaría nuestra argumentación, pues no debe olvidarse que en el chapadmalense «muéstranse interrupciones $\theta$ irregularidades producidas por denudaciones acaecidas en la misma época de la formación. Esas denudaciones han cavado depresiones o torrenteras que se han rellenado con limo de la misma formación que ya estaba endurecido $y$ fué arrastrado por las corrientes en forma do pequeños trozos rodados mezclados con limo más fino, de aspecto pulverulento» (Confr. AMEGHINO, Las formaclones, étc., 372 ).

${ }^{3}$ Acta, etc., 420. Recuérdese que el horizonte mesopampeano del Dr. Roth corresponde al ensenadenso de Ameghino; 
ha podido descubrir en ninguna parte un rellenamiento de zanja o caverna posterior a su formación» ${ }^{2}$. Contra esa opinión de los peritos se muestra sumamente indignado el Sr. Romero. Francamente no es explicable tal indignación en el campeón y legatario de la ciencia de Florentino Ameghino, puesto que según éste, «también acá, [ensenadense] como en la división inferior, [chapadmalense] se ven a diferentes niveles, lechos de antiguas corrientes de agua constituídos por fragmentos rodados de tosea y arcilla endurecida más antigua mezclados con huesos igualmente rodados - pertenecientes a mamíferos terrestres, pero no contienen huesos de peces ni conchas de moluscos». Esa es la causa de la formación de todos los estratos de tosquilla rodada que se encuentran en la región. No se formaron en el fondo del mar, sino que «se trata de lechos de corrientes de agua transitorias y no permanentes; es decir, que son del mismo carácter de las del horizonte chapalmalense» ${ }^{2}$.

En lo que respecta a la formación marina de ese chapadmalense que se aduce como prueba ilevantable de la imposibilidad de existencia de seres humanos en ese terreno, es otra teoría que, como la anterior del derrumbe de la barranca, nada autoriza a

1 Acta, etc., 422.

${ }^{2}$ AMEGHINO, Las formaciones, etc., 374. 
sustentar y que está rebatida de antemano por los propios argumentos que al fundarla se aportan.

En efecto: el hallazgo de un trozo de loess recogido entre «los materiales removidos, [por el Dr. Roth] al practicar la excavación» ${ }^{1}$, \& qué importancia puede tener en la discusión, desde que se trata de un trozo de procedencia desconocida, por mucho que figure entre los materiales de remoción de los trabajos del Dr. Roth?

Por de pronto, ignoramos cómo el Sr. Romero ha podido identificar ese trozo de loess con los materiales de remoción del Dr. Roth. Realizada su excursión cuatro años después de aquella remoción resulta sobremanera aventurada toda afirmación. Más dudas ocurrirán todavía si se tiene en cuenta que en la cubierta de su lámina III señala aquellos materiales de remoción en forma que de manera alguna puede ser aceptada. En efecto: dicha lámina III es reproducción de la fotografía tomada por la Comisión en el lugar de los hallazgos y en ella está patente la boleadora, lo cual demuestra que fué sacada antes de los trabajos del Dr. Roth que, como es sabido se realizaron después del regreso de los peritos a la capital ${ }^{2}$ : Cómo pueden, enton-

\footnotetext{
1 ROMERO, Ibid., 30.

2 ANIBAL CARDOSO, Breves noticias y tradiciones sobre el origen de la "boleadora» y del caballo en la República Argentina, en Anales del Museo Nacional de Historia Natural de Buenos Aires, XXVIII, 160, Buenos Aires, 1916.
} 
ces, figurar en esa fotografía los materiales de la remoción que señala el Sr. Romero?

Además, ¿ cómo pudiera ser identificado el material de remoción del Dr. Roth, después de transcurridos varios años, durante los cuales han acaecido no sólo las mareas comunes, sino también las altas mareas equinocciales? Bien es cierto que el Sr. Romero para nada las tiene presentes, siendo así que, dada la situación que ocupa el lugar que estudia, la influencia de las mareas y, sobre todo, de las equinocciales es causa principalísima de importantes modificaciones de las cuales un estudioso serio no puede dejar de preocuparse. En efecto: la destrucción de las costas por las mareas es demasiado sensible y, por lo demás, explica muchos de los hallazgos hechos por el Sr. Romero y que él juzga suficientes para invalidar las conclusiones del Acta. Según autor $\tan$ indiscutido como Lapparent, au moment oì la lame se brise contre le rivage, sa force vive est assez grande pour qu'elle puisse entraîner, d'une manière normale, non seulement des sables et des graviers, mais encore des galets de grosses dimensions. Ce n'est donc plus seulement de l'eau qui vient frapper la côte, c'est une véritable mitraille pierreuse, qui augmente par sa masse la puissance de l'élément liquide, et le rend capable d'effets destructeurs bien marqués; es así que sous 
cette action, les roches tendres se désagrègent ${ }^{1}$. $\mathrm{Y}$, sin embargo, después de haber sido repetidas veces golpeada la playa por esas mareas ha podido reconocer el Sr. Romero el disgregable material removido. Es sobremanera increíble tal afirmación.

$\mathrm{Y}$, puesto que hemos debido recordar los efectos de las mareas, $\&$ cómo no atribuir a éstas, igualmente, los numerosos restos de industria lítica encontrados - por el Sr. Romero-sólo cubiertos por «capas de arena» ${ }^{2}$ y a las cuales tanto valor atribuye en fundamento de su tesis? El mismo Lapparent nos dice que c'est dans le voisinage de la haute mer que l'action plongeante est la plus intense, il en résulte que, de tous les matériaux détritiques susceptibles d'être tenus en suspension dans la mer agitée, les plus gros seront ceux que la lame poussera les plus loin vers la terre ferme ${ }^{3}$. Es, pues, sumamente probable que todos esos objetos enteramente iguales y del mismo origen que los hallados por los peritos fueron arrebatados por las olas - en su obra de erosión - al loess de la barranca, quedaran en suspensión en las olas agitadas de las mareas y ainsi les galets s'accumuleront à peu

\footnotetext{
1 A. de LAPPARENT. Traité de géologie, $\nabla$ édition, 235. Paris, 1906.

2 ROMERO, Ibid., 36.

s LAPPAPENT, Ibid., 251.
} 
près au niveau de la haute mer ${ }^{1}$, en este caso, el cañadón donde luego los encontró el Sr. Romero para argüir con ellos contra las conclusiones del Acta con una gruesa ironía de suficiencia que hace aún más picante su imperdonable olvido de causas tan primordiales como las mareas.

Por añadidura, el loess que describe el Sr. Romero en nada se parece y por lo tanto nada tiene que ver con el loess que los peritos describen. Esta descripción, en todas sus particularidades, concuerda, por lo demás, con el loess típico señalado por Florentino Ameghino para esa región ², a pesar

1 LAPPARENT, Ibid., 251.

2 Los caracteres macroscópicos que los investigadores adjudi. can, respectiramente, al loess, son los siguientes:

«Las capas de este horizonte chapalmalense están constituidas por una arcilla muy fina, con muy poca cal distribuida en la masa, $y$ con poca arena... el conjunto es un loess en el sentido que se ha dado a esta palabra, aunque siempre mucho más duro y compacto que los depósitos de limo que en Europa se distinguen con el mismo nombre $y$ sin duda también de distinto origen» (Confr. AMEgHiNo, Las formaciones, etc., 369).
... «En general las toscas son mucho más escasas que en la parte superior; no obstante esto, el loess forma una masa muy consistente $y$ para cavar hay que hacer uso del pico y de la barreta. El aspecto general es el del loess de origen eólico, que está formado por minerales pulverizados muy homogéneos, $y$ en el que no se distinguen granos de arena a simple vista》 (Confr. Acta, etc. 421). 
de que piense lo contrario el Sr. Romero que, a línea seguida, confiesa no conocer el loess típico de Ameghino. Esa cándida osadía que, en todo su estudio, corre parejas con la insuficiencia científica del autor, culmina, poco más adelante, al afirmar que «en todo el bloque se ven innumerables agujeros de diámetro variable entre $1 / 4$ y 1 milímetro, que penetran la masa en todos sentidos, formando en su interior una serie de galerías generalmente desarrolladas en dirección de los planos de estraticicación, en los que se observan, mirados con el lente, elementos residuales de organismos que, sin duda alguna, constituyen deyecciones de anélidos, lo que demuestra en forma concluyente de que fué depositaảo en el fondo del mar durante el transcurso de muchos siglos, substraído por lo tanto a la acción directa de la vida continental» ${ }^{1}$. Recientes investigaciones ${ }^{3}$ comprueban, en efecto que el loess es una de las viviendas preferidas por los anélidos; pero es realmente inconcebible que, por la presen-

\footnotetext{
1 ROMERO, Ibid., 31. Sería, sin embargo, útil saber a ciencia cierta si tales deyecciones no han sido, por defecto de vista, confundidas por el Sr. Romero con ciertas otras, en forma de anélidos gigantescos y que es muy frecuente ver en los recodos de esas barrancas pero que, con evidente buen gusto, los visitantes esquiran prudentemente $y$, lejos de hacerlos objeto de un minucioso examen, omiten hasta el hacer mención de ellos.

2 M[OISES] KANTOR, Recherches océanographiques sur lo littoral maritime de la province de Buenos Aires (Communication préliminaire), en Anales de la Sociedad Cientifica Argentina, LXXXVI, 103, Buenos Aires, 1918.
} 
cia de deyecciones de esos anélidos, se deduzca que el loess se constituyó en el fondo del mar. Si aquellas deyecciones estuvieran en estado fósil, su presencia pudiera ser alegada como un testimonio. Pero siendo recientes, $i$ no son la prueba evidente de que los anélidos que allí las han dejado son actuales y que, en los últimos tiempos, han podido captarse el loess, porque éste ha estado expuesto a la acción de las aguas marinas? A pesar de esa evidencia que el más lego puede palpar, se afirma, sin embargo, que el trozo de loess, con sus deyecciones de anélidos, «demuestra en forma concluyente de que fué depositado [el piso chapadmalense] en el fondo del mar durante el transcurso de muchos siglos, substraído por lo tanto a la acción directa de la vida continental»! $Y$ eso se escribe diez años después de haberse constatado que «la ausencia de depósitos lacustres y la presencia exclusiva de torrenteras que no eran de agua permanente, prueban que en esa época esta regién de la provincia constituía un suelo elevado y seco» ${ }^{1}$.

Debe constar igualmente que los recientes estudios de Doering ${ }^{2}$ y De Carles ${ }^{3}$ acerca del loess y

${ }^{1}$ AMEGHINO, Las formaciones, etc., 373.

2 ADOLFo DOERING, Nota al estudio sobre la constitución geológica del subsuelo de la cuenca de Córdoba del Doctor Joaquín Frenguelli, en Boletin de la Academia Nacional de Ciencias en Córdoba (República Argentina), XXIII, 222, Córdoba, 1918.

3 ENRIQUE DE CARLES, Los vestigios industriales de la presencia del hombre terciario on Miramar, en Physis, Bevista de la 
toscas de la región de los hallazgos, ni siquiera insinúan un posible origen marino ${ }^{1}$.

Pero el colmo de la incompetencia y de la osadía no estriba en creer que las deyecciones de los anélidos se han conservado frescas durante todo el tiempo que media entre la deposición del chapadmalense hasta nuestros días; no consiste tampoco en suponer a ese piso de origen marino, a pesar de los estudios concluyentes de Florentino Ameghino que no debe desconocer el Sr. Romero; sino en ereer que sus despampanantes deducciones encuentran su confirmación en esos estudios, lo que le mueve a transcribir con gran regocijo de su parte algunos párrafos del gran sabio, en los que, dice, «hemos subrayado algunos renglones para llamar la atención sobre su importancia y acuerdo con nuestra tesis».

El párrafo transcripto es el siguiente:

Pendant les trois voyages d'étude à Mar del Plata que je fis dans le courant de l'année 1908, parmi

Sociedad Argentina de ciencias naturales, IV, 125 y siguiente, Buenos Aires, 1918.

1 Además el análisis químico ha determinado una composición casi idéntica para los loess submarinos y los continentales de la región. (Confr. ENRIQUE HERRERO DUCLOUX, Estudio químico de las "escorias» $y$ utierras cocidas», en FELIX F. OUTES, ENRIQUE HERRERO DUCLOUX y H. BUCKING, Estudio de las supuestas escorias $y$ tierras cocidas de la serie pampeana de la República Argentina. Revista del Museo de Ia Plata, XV (segun. da serie, II) 176. Buenos Aires, 1908; E. HERRERO-DUCLOUX, Résultats des analysis des Sables, Toscas, Loess et Eau de mer, en KANTOR, Ibid., 115. 
une foule d'objets et découvertes intéressantes, j'eus la bonne fortune de trouver une ancienne industrie de la pierre, différente de toutes celles connues jusqu'aujourd'hui.

Cette industrie vient du pampéen inférieur et la partie moyenne de l'ensénadéen, des couches éolomarines correspondant à la transgression marine interensénadéenne.

A Mar del Plata, l'interensénadéen est plaqué contre l'ancienne falaise constituée par le limon rouge et souvent très durci de l'étage chapalmaléen et de l'ensénadéen basal; il présente deux faciés distints: l'inférieur, exclusivement marin, qui correspond au plus haut niveau de l'Océan d'alors, - et le supérieur, constitué par un sable très fin, presque pulvérulent, mêlé à l'argile et à de petits fragments de coquilles triturées. Le matérial de ces couches supérieures est constitués par le sable très fin, la boue et les coquilles triturés que les vagues de la mer jetaient sur la plage et que les vents éparpillaient sur l'ancienne falaise et vers l'intérieur. Ce sont ces dépôts, de double origine, marine et éolienne, que j'ai désignés avec le nom d'éolomarins ${ }^{1}$.

$\mathrm{Ni}$ aún con la caprichosa puntuación introducida, el más desprevenido de los lectores podrá entender que sea el chapadmalense el piso que pre-

1 AMEghino, Une nouvelle, etc., 189. 
sente deux faciés. Bien claro está que l'interensénadéen es el sujeto de la primera frase y, por el pronombre $i l$, vuelve a serlo de la segunda. Es, pues, según Florentino Ameghino, el interensenadense el piso que presenta dos facies, la inferior de ellas de origen marino. Confundirlo con el chapadmalense, siendo éste de la serie araucana y aquél de la pampeana y mediando entre ambos nada menos que tres pisos y dos hiatos, es uno de los tantos ligeros errores de que está plagado el estudio del Sr. Romero y que hace suponer que éste es de los . que piensa[n] que la ciencia, lo mismo que la historia, es un conjunto de teorías, de relaciones y de cosas, al alcance del más osado» ${ }^{1}$.

Nada de inconcebible tendría, como se pretende, que la industria humana señalada por los hallazgos se hubiera mantenido a la misma altura durante largo lapso de tiempo. Pero, si se tiene en cuenta que ya en los primeros informes de Luis María Torres y Carlos Ameghino ${ }^{2}$ y en los posteriores de

\footnotetext{
1 ROMERO, Ibid., 31.

${ }^{2}$ LUIS MARIA TORRES y CARLOS AMEGHINO, Inform $\theta$ preliminar sobre las investigaciones geológicas $\mathrm{J}$ antropológicas en el litoral marítimo sur de la provincia de Buenos Aires, en Revista del Museo de La Plata, XX (segunda serie, VII), 158. Buenos Aires, 1913; LUIS MARIA TORRES $>$ CARLOS AMEGHI. NO, Investigaciones antropológicas 8 geologicas on el litoral ma-
} 
éste ${ }^{1}$ han comprobado una notable diferenciación de procedimientos técnicos en la fabricación de los diversos hallazgos, hay que convenir en que el Sr. Romero o desconoce completamente el asunto que ha abordado o bien voluntariamente oculta 0 tergiversa los hechos para asentar en algo, siquiera sea en patrañas, sus afirmaciones.

Pudiera ciertamente extrañar que en tan remoto tiempo existiera ya esa industria bastante adelantada ${ }^{2}$, tanto más cuanto que entre los diversos objetos nos ha dejado armas cuyo uso, según un dis-

rítimo sur de al provincia de Buenos Aires, en Boletín de la Socledad Physis para el cultivo y difusión de las ciencias naturales en la Argentina, I, 262, Buenos Aires, 1912 [1913].

1 CARLOS AMEGHINO, Los yacimientos arqueolíticos y osteoliticos de Miramar. Las recientes investigaciones y resultados referentes al hombre fósil, en Physis, IV, 21, Buenos Aires, 1918. En este artículo se reunen las Comunicaciones a la Sociedad Argentina de Ciencias Naturales, de fecha 3 de noviembre de $1917 \mathrm{y}$ 23 de febrero de 1918.

- Es de llamar la atención los hallazgos de alfarerías efectuados en diferentes ocasiones. C. AMEGHINO, Los yacimientos, etc., 25; W[ILLIAM] J. HOLLAND, To the River Plate and back, $199 \mathrm{y}$ siguientes. New York, 1913. El pasaje referente al descubrimiento ha sido traducido y publicado: El viaje del Dr. Holland a la Argentina. Hallazgo de trozos de alfareria on el pampeano de Mar del Plata, en Boletín de la Sociedad Physis para el cultivo $\nabla$ difusión de las ciencias naturales en la Argentina, I, 475. Buenos Aires, 1912 [1914]. Asimismo el Dr. Holland publicó un resumen de su viaje en The Pittsburgh Gazette - cuyo original inglés no conocemos-en que hace mención de las alfarerías del pampeano; fué reproducido en versión catellana: Impresiones de la Argentina. Un artículo del Dr. W. J. Holland, en La Nactón, 9 de marzo de 1913. Buenos Aires. 
tinguido investigador, fué introducido en estas tierras en tiempos completamente históricos ${ }^{1}$. Pero

1 [ROBERT LEHMANN NITSCHE], Junta de Historia $\boldsymbol{y} \mathrm{Nu}$ mismática. «El origen de las boleadoras y del lazo», en La Prensa, Junio 17 de 1918. No 17.686. Buenos Aires.

Hacemos referencia a esta crónica porque en ella se afirma «que está comprobado que las boleadoras fueron primeramente usadas por los esquimales de Alaska y Groenlandia». Aunque este párrafo no conste textualmente en el texto de la conferencia ( $R$. LEHMANN NITSCHE, Costumbres nacionales. El origen de las boleadoras y del lazo, en Ia Unión, 31 Julio, 1 Agosto de 1918. Nos. 1155,1156 ) es conveniente desvirtuar desde ya toda torcida interpretacion que quiera darse a aquella conclusión. Baste expreear la imposibilidad histórica de asignar tal origen a las bolea. doras ya que el uso de tales armas por algunas tribus aborigenes del Río de la Plata ha sido consignado por los primeros conquis. tadores que tuvieron ocasión de frecuentarlos. (Confr. LUIS RAMIREZ, Carta de... [puerto de san zalbador (sic) a. diez. dias del mes. de. julio de 1528 años], en EDUARDO MADERO, Yistoria del Puerto de Buenos Aires, segunda edición, 399, Buenos Aires. 1902; ULRICH SCHMIDEL, Viaje al Rio de la Plata (1534-1554), 150, Buenos Aires, 1903). Por otra parte el mismo autor de la tesis que comentamos parece olvidar lo sus. tentado al hacer referencia a los cementerios de la poblacion indigena - en los alrededores de Trelew - «que indudablemente, a juzgar por los caracteres muy típicos del esqueleto, son los antecesores de los famosos Patagones o Tehuelches actuales» $y$ en la que hace constar que la industria litica estaba representada, entre otros objetos, por «boleadoras de piedra». En cuanto a la edad de los restos humanos, como si no bastara la presunta ascendencia que les atribuye, el autor hace conocer que en los enterratorio. *no se hall6 nada que indicara la influencia europea). (Confr. ROBERT LEHMANN NITSCHE, La artritis deformans de los an. tiguos patagones. Contribución a la antropo-patología, en Revista del Museo de La Plata, XI, 200, La Plata. 1904 [1903]).

La opinión sustentada por Lehmann Nitsche en la Junta de Historia y Numismatica Americana ha sido enteramente tergiversada en una recientísima publicación (MARTINIANO LEGUIZAMON, Etnografía del Plata. El origen de las boleadoras $\bar{y}$ del 
si admitimos, con la conclusión del Congreso de Tucumán ${ }^{1},-$ y nada fundado se ha objetado en contra ${ }^{2}$ - que los hallazgos se han realizado in situ, será forzoso reducir a su relativo valor unas teorías contra las cuales deponen en forma terminante los hechos comprobados.

lazo, en Revista de la Universidad de Buenos Aires, XLI, 213; $y$ en Publicaciones de la sección antropológica de la Facultad do Filosofía y Letras, No 19, pág. 10. Buenos Aires, 1919) que, aunque nacida al amparo de la Sección Antropológica de la Facultad de Filosofía y Letras, no es más que una desgraciada rapsodia, en la cual el autor manifiesta una sorprendente incapscidad para ver claro. Tantos son los trocatintas e incongruencias que allí se deslizan que se hará obra de caridad - con el autor y con el público - en no analizarla.

- Reseña general de la Primera Reunión Nacional de la Soctedad Argentina de Ciencias Naturales. Tucumán, 23-30 de noviembre de 1916, en Anales de la Sociodad Cientifica Argentina, LXXXIII, 150. Buenos Aires, 1917. Edición de la Sociedad Ar. gentina de Ciencias Naturales, 38. Buenos Aires, 1917; [CARLOS GUTIERREZ]*, Notas cientificas. El hombre de Chapaimalal. Sanción plena, en La Nación, 15 de diciembre de 1916. Buenos Aires. Primera reunión nacional de la Sociedad Argentina de Ciencias Naturales. Tucumán, 1916. Sección II. Paleontología. 183. Buenos Aires, 1919. Consúltese también: [ENRIQUE M. HERMTTTE], Memoria de la División general de Minas, Geología o Hidrología correspondiente al año 1916 en Anales del Ministerio de Agricultura, Sección Geología, Mineralogia \& Minería, XIII, Yúm. 5, 48. Buenos Aires, 1919.

2 GCIDO BONARELLI, Sobre los hallazgos paleoetnológlcos do Miramar, en Physis, Revista do la Sociedad Argentina de ciencias naturales, IV, 339, Buenos Aires, 1918. No puede adjudićrsele a la comunicación un ralor excepciorral, sino, tan sólo, el de simple disidencia personal, la que, por otra parte, no ha sido abonada por clase alguna de prueba.

* La mención del nombre del autor, responde a que éste lo hizo conocer al público lector. CARLOS GUTIERREZ, Mitre arqueólogo, en La Nación 19 de enero de 1917, nota 13. Buenos Aires. 
No es el caso de insistir aquí nuevamente en las razones que nos mueven a creer que los hallazgos se realizaron in situ, como afirma el Acta de los peritos y reconocen las conclusiones del Congreso de Tucumán. Ya se han dado algunas al refutar la opinión contraria del Sr. Romero. Pero será oportuno tener presente que el hallazgo de un fémur de Toxodonte (?) con una flecha incrustada ${ }^{1}$, por el hecho de haber sido encontrado articulado con los demás huesos de la pierna, como también se encontraron articuladas varias vértebras dorsales, flechadas igualmente", no sólo comprueba la situación primaria de los objetos, sino también la coexistencia del hombre con aquel animal. Tan concluyente es esto que bien nos explicamos el crispamiento de

1 CARLOS AMEghiNo, El fémur de Miramar. Una prueba ms. de la presencia del hombre en el terciario de la República Argentina. Nota preliminar, en Anales del Museo Nacional de Historl Natural de Buenos Aires, XXVI, 333. Buenos Aires, 1915; [OARLOS GUTIERREZ], Notas cientificas. El origen del hombre. Revelación sensacional, en La Nación, 22 de noviembre, 1914. Buenos Aires; [CARLOS GUTIERREZ], Notas científicas. El Tozodon revelador, en La Nacion, 27 de diciembre, 1914. Buenos Aires.

2 [CARLOS GUTIERREZ], Notas cientificas. Revelaciones prohistóricas. Nuevos descubrimientos de Ameghino. Una comprobación excepcional, en La Nación, 3 de mayo, 1916. Buenos Aires; [CARLOS GUTIERREZ], Notas clentificas. El hombre de Chapalmalal, en La Nací́n, 10 de mayo, 1916. Buenos Aires; Reser. general de la Primera Reunión, etc., 37 y siguiente del tirajo aparte. CARLOS AMEGHINO, La cuestión del hombre terciarto on la Argentina. Resumen do 108 principales descubrimientos hechos después del fallecimiento de Florentino Ameghino, en Primera reunión, etc., 164. 
nervios con que un eminente paleontólogo europeo ha recibido la noticia del descubrimiento ${ }^{1}$; tan concluyente que, para formular una crítica con apariencia de seriedad, otro investigador ha tenido que recurrir a la estratagema de ocultar que los huesos aparecieron articulados, pudiendo así enunciar la pueril hipótesis de que el fémur, por movimientos de loess, equivalentes a los de los médanos, pudo quedar en descubierto en épocas cercanas, oportunidad que aprovechó un salvaje para incrustarle la flecha, volviendo luego el fémur por desconocidas causas, a sepultarse de nuevo en el terreno que le correspondía ${ }^{2}$.

El Sr. Romero no necesita improvisar hipótesis tan peregrinas para restar toda importancia al descubrimiento del fémur. A él le basta, inventar una supuesta desinteligencia entre el Acta de los periritos y la exposición de D. Carlos Ameghino, para sentenciar que el fémur no pudo ser hallado en el piso chapadmalense. Tan supuesta es esa desinteligencia que, para suponerla, ha debido adulterar

\footnotetext{
1 M[ARCELLIN] B[OULE], Encore l'Homme miocène dans l'Amerique du Sud, en L'Anthropologie, XXVI, 191. París, 1915.

2 ALCIDES MERCERAT, Las formaciones eolíticas de la República Argentina. Indicaciones preliminares para la resolución de los problemas fundamentales, referentes a sus relaciones fisiográficas, petrogenéticas $y$ cronológicas, on correlación con la antigüledad del hombre, en Estudios, Revista mensual redactada por la Academia Literaria del Plata, XII, 244. Buenos Aires, 1917, tiraje aparte, 6 .
} 
textos, bien que, como protesta anticipada contra la más que segura incredulidad de los lectores se atreve a decir inmediatamente antes de presentar la versión adulterada que la publica porque «pudiera sospecharse por los que no la conocen, que nosotros la inventamos si nos referimos únicamente a ella». Esa adulteración es tan grosera que hace inútil el cotejo. Va a continuación, sin embargo, para ejemplo de aficionados y muestra de la seriedad con que debe tomarse a un militar del viejo ejército metido a naturalista.

«En este lugar (se refiere a la parte culminante de la barranca) fué donde encontramos la pieza reveladora de que nos ocupamos (el fémur de un toxodonte). Se hallaba aproximadamente a unos cinco metros sobre el nivel de la playa del mar y cerca del límite o discordancia con el piso chapalmalense. Las condiciones del yacimiento se presentan, pues, perfectamente claras, sin que pueda haber al respecto la menor duda» ${ }^{1}$.
«Luego, continuando la revisión minuciosa de la barranca, que, a partir del depósito de las piedras trabajadas consignado en el Acta, se eleva paulatinamente hacia el nordeste, coleccionanos numerosos fósiles del horizonte chapalmalense, $y$ entre ellos algunos de los más característicos del piso, tales como los géneros $P a$ chyrucos y Dicoelophorus, que faltan en el terreno pampeano que viene inmediatamente encima.

La naturaleza y relación estratigráfica de las capas

${ }^{1}$ ROMERO, Ibid., 32. Lo que está entre paréntesis son anotaciones explicatorias del Sr. Romero. 
que lo forman, son en ese acantilado casi iguales a las del punto descripto en el Acta, es decir, que los dos horizontes se presentan igualmente a la vista: el chapalmalense en la base $y$ el ensenadense en la cúspide; pero la discordancia entre ellos ya no es tan clara $y$ perceptible, debido sobre todo a una coloración parecida en el loess de los dos horizontes superpuestos.

La diferencia que puede notarse, por lo que se refiere a la disposición de las capas con respecto al lugar típico descripto en el Acta, es la de que aquí el chapalmalense surge visiblemente en el perfil de la barranca más hacia arriba y va a constituir la cumbre de la antigua loma después denudada que se menciona en aquélla. Además, a causa do este mismo surgimiento del chapalmalense en el corte de la barranca, resulta que el piso ensenadense que viene arriba presenta un menor espesor. 
En este lugar fué donde encontramos la pieza reveladora de que nos ocupamos. Se hallaba aproximadamente a unos cinco metros sobre el nivel de la playa del mar y cerea del límite o discordancia con el piso ensenadense, pero en pleno piso chapalmalense. Las condiciones de yacimiento se presentan, pues, perfectamente claras, sin que pueda haber al respecto la menor duda» ${ }^{1}$.

La adulteración del texto de Carlos Ameghino así como el pretender que allí se describe el mismo lugar de que informa el Acta tiene su razón de ser, pues según el corte de la barranca que presentan los peritos, no correspondería al chapadmalense el decubrimiento del fémur, ya que, en ese sitio, por movimientos tectónicos no "alcanza en su parte integral de los cinco metros de potencia que le asigna»" (sic!) Carlos Ameghino en el lugar en que el hueso fué descubierto.

Finalmente, el Sr. Romero alega, como prueba de que no fué en el chapadmalense donde se realizó el hallazgo del fémur Toxodon (?) con el trozo de cuarcita incrustada, la presencia de torrenteras de

1 C. AMEghiNo, el lémur, etc., 438.

2 ROMERO, Ibid., 34. Entiendes, Fabio? 
denudación sobre la superficie del chapadmalense, a las cuales atribuye un origen marino e identifica, en el mismo proceso de rellenamiento "por obra de la acción del mar» con las numerosas cuevas que existen en la barranca y que están «rellenadas totalmente por sedimentos que difieren por su color del loess del estrato en que han sido abiertas» ${ }^{2}$. Respecto al crigen marino atribuído a las denudaciones, más arriba se ha visto que Florentino Ameghino considera, basándose precisamente en la presencia de torrenteras de denudación sin vestigios orgánicos, que el terreno era elevado y seco. Y en cuanto a las cuevas descubiertas por el Sr. Romero y de cuya «grandísima importancia», para comprobar el origen marino él solo se percata, débese recordar que la deducción de que esa región de la provincia constituía un suelo elevado y seco «se confirma también por la presencia en distintos niveles de la formación de cuevas más o menos cilíndricas que sirvieron de habitación a los Pachyru cos, Dicoelophorus y otros mamíferos de esa época. Esas cuevas están rellenadas por un limo muy fino estratificado en estratos muy delgados y no es raro encontrar en ellas esqueletos completos de los animales que las habitaron» .

1 ROMERO, Ibid., 26.

${ }^{2}$ AMEGHINO, Las formaciones, etc., 373. 
Los objetos encontrados, además, tienen para el Sr. Romero una procedencia bien distinta de la que les ha sido atribuída. Lejos de ser vestigios de una industria humana en el chapadmalense, ellos han sido trabajados y usados por una población aborigen, que en tiempos no muy remotos vivía a la orilla de una laguna que existió sobre la barranca. No dice explícitamente qué causas le han hecho conocer la existencia de dicha laguna, pero, a lo que parece, ya que es necesario proceder por inferencia, ella está denunciada por la presencia de «depósitos lacustres, que dan fe y evidencian la existencia de una laguna profunda y extensa». Esos depósitos se encontraban «sobre la barranca» y fueron descubiertos «al subir la pequeña pendiente del valle transversal de los mentados descubrimientos». «El que haya visitado ese lugar - agrega - podrá confirmar este hecho; pero no ocurre así para los que han de atenerse a los informes del Acta y a la opinión en disidencia planteada por C. Ameghino, que no hacen mención de un hecho de tantísima importancia» ${ }^{1}$.

Por lo anteriormente dicho, se sabe que Carlos Ameghino no plantea ninguna disidencia, puesto que, como describe un lugar distinto al que se consigna en el Acta, es lógico que las dos descripciones difieran, como es también natural que nada diga

1 PeOMERO, Ibid., 34 y siguieute. 
respecto a esos depósitos que no existen en el lugar que él estudia. Pero si Carlos Ameghino no los cita, no puede decirse otro tanto del Acta. En efecto; los peritos informan que «en la pendiente noroeste hay en la parte superior de la barranca un depósito de loess freático con pequeños rodados de tosca y arena que corresponden probablemente al piso lujanense» ${ }^{1}$. Todo indica que estos estratos son los mismos a que se refiere el Sr. Romero, puesto que, no sólo son los únicos depositados sobre el ensenadense, además de coincidir con el lugar que él indica, sino también por el hecho de que el lujanense está constituído por depósitos lacustres.

Es fácil comprobar, con auxilio de los estudios de Florentino Ameghino, esa identificación de los depósitos del lujanense de los peritos con los estratos lacustres del Sr. Romero. Este, en apoyo de su teoría, añade que los depósitos marinos y fluviales de Las Brusquitas «resultaron de gran interés para nuestras investigaciones, relacionándose principalmente con la laguna desaparecida en que se encuentran los artefactos, arrojando a su respecto completa luz sobre su existencia y época probable de su desaparición»?. Esto es precisamente lo que justifica aquella identificación, ya que «en cuencas de erosión al través del bonaerense, aparecen depó-

\footnotetext{
1 Acta, etc., 420.

2 ROMERO, Tbid., 38.
} 
sitos verdosos, ya marinos, ya lacustres (boca del Chapalmalán, Las Brusquitas, Miramar, etc.), que representan el horizonte lujanense y la transgresión marina correspondiente» ${ }^{3}$. Se ve, pues, con cuánta razón, bien que equivocándose gravemente en las conclusiones, puede el Sr. Romero señalar la existencia de depósitos, a veces marinos, y a veces, fluviales.

Desechado el argumento geológico en que funda su tesis, no estará de más consignar el valor del argumento paleontológico que también aporta el Sr. Romero para sustentarla. Este es nulo, ya que los errores que en él se deslizan superan en mucho a todos los hasta ahora consignados. Así puede notarse que se designa una especie con el nombre de Solen curtus, palabras que, unidas y suprimida una letra, constituye el nombre del género respectivo, llamado Solecurtus platensis Orb., el cual, por otra parte, tampoco debiera citarse ya que ha sido identificada con el Tagelus gibbus Spengl., y que ha sido señalado en la región ". Indica también la presencia de la Ostrea parasitica $\mathrm{Gm}$. - no arborea Ch. que es sinónima - y la Ostrea puelchana Orb. - no puelcha que escribe el Sr. Romero, - la pri-

1 AMEGHYNO, Las formaciones, etc., 412.

' H[ERMANN] VON IHERING, Mollusques du pampéen do Mar del Plata et Chapalmalán recueillis par $\mathbf{M}$. Lo Dr. Florentino Ameghino en 1908, en Anales del Museo Nacional do Buenos Aires, [XVII], serie III, X, 437, Buenos Aires, 1909 [1908]. 
mera de las cuales es característica del pampeano superior como lo es la segunda del postpampeano ${ }^{1}$, especies que no han sido reconocidas en esa parte ni por Florentino Ameghino ni por v. Ihering y que, de ninguna manera pueden ser contemporáneas, y, por lo tanto, no pueden aparecer juntas.

Resulta, en consecuencia, evidente que la teoría de la laguna que sustenta el Sr. Romero carece de fundamento y que los depósitos lacustres de la barranca son exclusivamente los estratos del lujanense. Pero como a él, según luego se verá, para presentar mayor objeciones al Acta, no le conviene reconocer la presencia del lujanense, se extiende largamente a explicar la formación de la supuesta laguna $\mathrm{y}$, entre otras cosas, dice que la laguna se habría formado sobre el acantilado de los artefactos «a medida que las aguas del mar se retiraban» ya que «es sabido que el agua del mar rechaza a la del río»". Sabido es, en efecto que, como en la copla de los sarracenos que nos molieron a palos, el agua del mar cuando tiene más fuerza, rechaza a la del río, como ésta, a su vez, cuando es más potente rechaza a aquélla, como se observa en la desemboca-

${ }^{1}$ H[ERMANN] VON IHERING, Historia de las ostras argentinas, en Anales del Museo Nacional de Buenos Aires, VII, 120 y siguientes, Buenos Aires, 1902; H. von IHERING, Les mollusques fossiles du tertiaire et du crétacé supérieur de l'Argentine, en Anales del Museo Nacional de Buenos Aires, [XIV], serie III, VII, 425 y siguiente. Buenos Aires, 1907.

2 ROMERO, Ibid., 40. 
dura de caudalosos ríos como el Amazonas, Congo, Plata y otros.

La misma seriedad presenta la explicación de la desecación de la laguna. El desecamiento se habría operado a causa del descenso de la costa, deseenso provocado por la acción de la mar «como lo demuestra el ataque intenso a la barranca, que paulatinamente continúa desmoronándola y penetrando cada vez más al interior y acumulando masas de arena que tan pronto la invaden y nivelan como son arrastradas en otro nuevo impulso». Todo lo contrario, sin embargo, se afirma en un reciente estudio de acuerdo con el cual parece ser indudable que actuellement, la mer pasait être, pour toute la région, dans une période de régression ${ }^{1}$.

Pero sea verdad lo uno o lo otro, quedaría inexplicada la causa por la eual los objetos trabajados y usados por los aborígenes que se instalaron al borde de la laguna, fueron encontrados a mayor profundidad que la del lecho de ésta, siendo así que, según las hipótesis del Sr. Romero, el piso en que se hallaron, por ser de origen marino, debería estar ya sedimentado en la época en que según él se formó la laguna al retirarse las aguas del mar.

${ }^{1}$ KANTOR, Ibid., 96. 
Vuelta de nuevo al estudio del terreno.

Este no puede ser el señalado por los peritos porque kel trozo de barranca de los artefactos no está constituído por los elementos de que informa el acta» ${ }^{3}$. Y no puede estar constituída por esos elementos porque en los $\ll 5$ metros escasos de altura... los peritos han encontrado acumulada y perfectamente definida, toda la serie completa de las formaciones que se han sucedido desde el cenozóico medio hasta el pleistoceno superior, durante un transcurso de tiempo tan inmenso que sus depósitos forman montañas» ${ }^{2}$. Esas montañas de sedimentos reducidas a un cuadro, son las que para el Sr. Romero «demuestra[n] con claridad el absurdo de tal pretensión» ya que «no se concibe que estas condiciones pudieran realizarse aisladamente en un punto limitadísimo sobre una superficie casi horizontal que ocupa miles de kilómetros sin que en toda ella se encuentren, ni juntas ni aún aisladas, las formaciones señaladas por los peritos en «dicho lugar»"

Con objeto de no alargar demasiado estos apuntes de ligera crítica, no hay para qué reproducir el testimonio de numerosos estudiosos tanto europeos como americanos que han comprobado hasta qué

\footnotetext{
${ }^{1}$ ROMERO, IBId., 11.

2 ROMERO, IBid., 42.

a ROMERO, TBId., 49.
} 
punto, en una reducida altura, pueden encontrarse sobrepuestas las diversas series de estratos. Bastará, para concretarnos a la región descripta por el Sr. Romero, remitir al lector a la monografía del Dr. Ameghino, en cuyos esquemas ${ }^{1}$ puede verse, con simple ojeada, como precisamente en las cercanías del lugar estudiado, se hallan representadas y hasta sobrepuestas todas las series indicadas por los peritos y que el Sr. Romero asegura no se encuentran ni juntas ni aisladas en una superficie de miles de kilómetros!

Por lo demás no es ciertamente en el Acta donde se encontrará la afirmación de que los cuatro horizontes, eopampeano (hermosense y chapadmalense de Ameghino), mesopampeano (ensenadense), neopampeano (bonaerense y lujanense) y postpampeano (platense), se encuentran en la barranca sobrepuestos los unos a los otros. Según el Acta, en la barranca se encuentran completamente sobrepuestos el ensenadense sobre el chapadmalense, mientras que el lujanense está denunciado, en la pendiente noroeste de la barranca, por un depósito de loess freático. A más, el valle transversal está rellenado por sedimentaciones neopampeanas y postpampeanas.

1 AMEghiNo, Las formaciones, etc., fig. 4, 366, y muy especialmente figs. 5 y 6 , - corte tranaversal del arroyo Chapalmalán, - 378 y siguiente. 
Prueba más concluyente (?!) de que la barranca no puede estar constituída por los elementos que se mencionan en el Acta, consiste, sin embargo en las numerosas contradicciones en que incurren los peritos. "Tan pronto afirman que el mesopampeano tiene de 20 a 30 metros de espesor en la provincia de Bucnos Aires y que en Salta y Tucumán pasa de 200 metros, como se le asigna 4 metros en la «barranca que nos ocupa»; lo que significa que las demás formaciones: postpampeano, neopampeano y eopampeano, quedan sometidas a constituir con sus depósitos el metro restante de la altura de la barranca; y, a renglón seguido, se dice que «así como la falta completa del loess del horizonte neopampeano en la cumbre demuestra que el paraje formaba una loma, etc.». En cuanto al eopampeano (reducido al chapalmalense), los peritos nos dicen que tiene tres metros y Carlos Ameghino que tiene cinco» ${ }^{2}$.

La primera de las contradicciones denunciada por el Sr. Romero, sirve tan sólo para demostrar una vez más la escasa preparación con que ha abordado un tema para cuyo estudio carece de la indispensable versación. Si él estuviera al corriente de los estudios que sobre la geología argentina se han realizado desde hace ya algún tiempo, no ignoraría que il faut admettre évidemment que la puis-

1 ROMERO, Ibid., 43. 
sance relative des diverses couches pampéennes, va en diminuant avec le niveau, depuis la Cordillère jusqu'au littoral. Nous ne devons donc pas être surpris de ce que la puissance des couches de l'étarge supérieur soit plus considérable à Córdoba qu'à Buenos Aires. '.

Posteriormente, basado en prolijos y numerosos estudios se ha dicho que «si existe conexión entre la formación de las gruesas capas del loess en las partes montañosas del poniente, donde, en algunos puntos, se han acumulado en series con espesor de varios millares de metros, y a la distribución del manto de loess en el litoral, se puede contar con un espacio de tiempo mucho mayor que si el loess 110 fuera otra cosa más que el producto más fino lavado de las morenas cuatemarias y llevado por el viento. Lo decisivo es la formación del loess. Durante todo el tiempo que ha tenido lugar, el loess ha sido transportado de la región andina hacia el naciente» ${ }^{2}$. Ese es el valor de la primera contradicción.

${ }^{1}$ ADOLPHE DOERING, Ia formation pampéenne de Córdoba, en ROBERT LEHMANN-NITSCHE, Nouvelles recherches sur la formation pampéenne et l'homme fossile de la République Argentine. Revista del Museo de La Plata, XIV, (segunda serie, I), 187. Buenos Aires, 1907.

${ }^{2} J$ [UAN] KEIDEL, La geología de las sierras de la provincia de Buenos Aires y sus relaciones con las montañas de Sud Africa y los Andes, en Anales del Ministerio de Agricultora de la Nación. Sección Geología, Mineralogía y Minería, XI, No 3, 45. Buenos Aires, 1916. 
Según se ha visto anteriormente, aún admitiendo la altura de 5 metros que el Sr. Romero calcula a la barranca ${ }^{1}$, no son tres horizontes, postpampeano, neopampeano y eopampeano, los que quedan sometidos a constituir un solo metro de altura. Se ha visto que el postpampeano y neopampeano no contribuyen a la altura de la barranca, pues el uno se encuentra en la pendiente noroeste y en el valle transversal y el otro tan sólo en ese valle. De ahí también que no exista contradicción alguna en la falta completa de loess del horizonte neopampeano en la cumbre, ya que, aunque resultc pesado insistir, este horizonte aparece en la vertiente noroeste $\mathrm{y}$ en el valle transversal. En cuanto a la divergencia de Carlos Ameghino, ya está dicho que, como él describe un lugar distinto al del Acta, forzoso es que consigne las diferencias que hay entre ambos. A esto han venido a parar las numerosas contradicciones...

Prosigue el trabajo del Sr. Romero con la comparación entre los hallazgos realizados por la comisión al Sud de Miramar. Según él esos objetos «son contemporáneos con los que se encontraron al sur del arroyo Las Brusquitas». Básase para afirmar

\footnotetext{
${ }^{1}$ La cifra de cinco metros de altura que so adjudica a la barranca, es del Sr. Romero; los peritos no mencionan dicha altura, como tampoco señalan al chapadmalense una potencia do tres metros, a pesar de lo que diga en contrario el autor del artículo que nos ocupa.
} 
esa contemporaneidad, contraria a la opinión de los peritos, en las discrepancias que encuentra entre el Acta y la descripción de esa barranca becha por Florentino Ameghino. Cotejando el texto del Acta con esa descripción se podrá juzgar si existe discrepancia alguna.

«Las barraneas de 10 a 15 metros de alto que se encuentran en el mismo pueblo de Miramar y se extienden hasta Punta Hermengo, se parecen a las barrancas del Norte de Mar del Plata, estando constituídas, como estas últimas, por el ensenadense que comprende más o menos los dos tereios inferiores, $y$ el bonaerense el tercio superior. Sin embargo, en el punto más próximo a Miramar, la barranca deja ver en su parte superior un gran depósito lacustre de color verdoso con muehos fósiles en la parte inferior que corresponde al fondo de la antigua laguna. Este depósito es probable corresponda al horizonte lujanense. Sobre este depósito lacustre se oxtiende una serie de capas marinas, muy delgadas, de color obscuro, perfectamente
«La base de la barranca está formada por depósitos de loess del horizonte mesopampeano; encima se hallan capas lacustres de eolor gris elaro verdoso con rodados y tobas calcáreas del horizonte neopampeano. Entre los dos horizontes se nota una discordancia bien definida, como se puede ver en la lámina XXII, figura 5 . Encima de todo existe una capa de sedimentos lacustres postpampeanos de poco espesor. Entre estos dos horizontes no se observa ninguna discordancia, pero se puede distinguir un depósito del otro por varias circunstaneias, v.gr.: que los ultimos están mezclados con tierra vegetal, mientras que en el otro falta toda materia orgánica.

No hay duda que la boleadora se encontró en po- 
horizontales y de una gran sición primaria y en una caregularidad; corresponden a pa lacustre muy pura que la transgresión marina más correspondería al piso lujareciente designada con el nense según la declaración nombre de querandinenses '. de Carlos Ameghino y Roth. La existencia del hombre de este período geológico está bien comprobada por muchos hallazgos de restos humanos $y$ artefactos, de manera que la Comisión opina que, ya por eso, la boleadora de que se trata debe considerarse correspondiente al horizonte neopampeano» ?.

Notorias son para todos las concordancias existentes entre ambas descripciones. En ambas se afirma que la base de la barranca está constituída por ensenadense. Sobre el ensenadense, Florentino Ameghino señala al bonaerense y sobre éste el lujanense; el Acta coloca sobre el ensenadense al neopampeano de Roth que, como es sabido, comprende el bonaerense y lujanense de Ameghino. La presencia del lujanense está, además, netamente consignada por cuanto allí se afirma que la boleadora ha sido encontrada en dicho terreno. Esto no obstante, el Sr. Romero, con la persistente mala fe y voluntaria tergiversación con que ha tramado todo.

1 AMEGHINO, Las formaciones, ete., 380 y siguiente.

Acts, etc., 424. 
su trabajo, encuentra discrepancias entre ambas descripciones, pero para encontrarlas ha debido recurrir a un medio que no hay por qué calificar y que demuestra su honestidad científica: truncar el Acta, de suerte que la barranca aparezca formada exclusivamente por el ensenadense ${ }^{*}$.

Finalmente, y para estar en algo de acuerdo con el Sr. Romero, en tesis general puede aceptarse que el material con que están hechos los hallazgos no indica contemporaneidad entre dicho material y los artífices que los trabajaron. Eso es indudable. Pero en el caso actual, motivos hay y sobrados para establecer la coexistencia entre los artífices y los animales con cuyos huesos fueron elaborados algunos de los objetos. Téngase presente, que algunos de los hallazgos demuestran que los huesos fueron trabajados o manipulados en fresco. Tal es, por ejemplo, el fémur con el trozo de cuarcita que no pudo ser introducida estando ya el hueso en estado fósil. Otro tanto las vértebras flechadas del mismo Toxodon (?). Más recientemente, los huesos de un gravígrado del género Lestodon astillados y tritu-

1 Los últimos estudios de Carlos Ameghino comprueban que ha existido error por parte de la comisión en considerar como lujanense lo que es ensenadense, habiéndose podido llegar a esta determinación por el descubrimiento de restos de Typotherium cristatum. (Confr. O. AMEGHINO, Los yacimientos, etc., 21). Pero no debe olvidarse que no es a este estudio de Carlos Ameghino al que se refiere el Sr. Romero sino al Acta de los peritos, y, en ella, si no se truncan sus párrafos, se indican los mismos terrenos ceñalados por Florentino Ameghino. 
rados en forma sospechosa ${ }^{1}$. Y si no quiere admitirse valor probatorio a todos esos ejemplos por tratarse precisamente de hallazgos a los cuales se pretende quitar toda importancia, recuérdese que ya Florentino Ameghino estudió numerosos huesos de animales coetáneos del Toxodon y aún anteriores que se encontraron hendidos y triturados en forma tal, que demuestran acabadamente la contemporaneidad del hombre con aquellos animales.

Estas notas, escuetamente presentadas, sin ilación y sin método, porque se concretan a señalar los errores del Sr. Romero, a medida que se presentan, no tienen otra pretensión que la de demostrar que el artículo que las motiva, explicable como lamento de despechado, contiene afirmaciones tan inadmisibles, tergiversaciones tan audaces que ni la misma ignorancia las excusa. No hay allí una sola observación de importancia que, por incompetencia o mala fe, no se presente falseada; una sola conclusión que, en el mejor de los casos, no se reduzca a una simple hipótesis insostenible; una sola crítica que no degenere en diatriba.

Así y todo, si estas notas bastan - y, tal vez, sobren - para que el trabajo del Sr. Romero quede reducido a su verdadero y escasísimo valor habrán

1 C. AMEGHINO, Iros gacimientos, etc., 19. 
llenado su objeto, y, en modo alguno, deben ser consideradas como una defensa de las conclusiones a que arriba el Acta de los peritos. La seriedad y los conocimientos de éstos no necesitan de abogados oficiosos, ni, por otra parte, pueden ser alcanzados por los cascotazos del Sr. Romero.

Respecto a los hallazgos de Miramar y a su significado para la determinación precisa de la edad del hombre, será prudente, por el momento, contentarse a comprobar, con el Congreso de Tucumán que «los elementos actuales de juicio no son suficientes para resolver respecto de la edad de los terrenos en que se encuentran los objetos arqueológicos, presentados por el Sr. Carlos Ameghino, como procedentes del piso chapalmalense de Miramar y cuya autenticidad ha quedado comprobada» y suspender todo juicio hasta que «se proceda a efectuar investigaciones geológicas comparativas y fisiográficas» ${ }^{2}$.

Sólo se llegará a la consecución de la verdad observando esa prudente conducta y siguiendo una senda equidistante de la aventurada fantasía y del prejuicio empecinado. Así proceden los verdaderos estudiosos, de lo cual nos da ejemplo el Sr. Carlos Ameghino quien, recientemente, con amplio espíritu de tolerancia que merece ser señalado, no vacila

\footnotetext{
1 Besef́a general de la Primera Reunión, etc., 38; Primera rounion, etc., 183.
} 
en postergar tal vez íntimas convicciones, para poner sus conclusiones a la par de las del Congreso de Tucumán, defiriendo para más minuciosas comprobaciones la sentencia definitiva ${ }^{\mathbf{1}}$.

${ }^{2}$ C. AMEGHINO, Los yacimientos, ote., 27. 
1 
SMITHSONIAN INSTITUTION LIBRARIES 